\title{
Spatial and Temporal Variation of Soil Water Movement Modeling under Line Source Dripper
}

\author{
R. Rahul ${ }^{1 *}$ and M. Manikandan ${ }^{2}$ \\ ${ }^{1}$ Department of Soil and Water Conservation Engineering, ${ }^{2}$ Department of Irrigation and \\ Drainage Engineering, Agricultural Engineering College and Research Institute, Tamil Nadu \\ Agricultural University, Kumulur - 621712, Trichy, India \\ *Corresponding author
}

\begin{abstract}
A B S T R A C T
An attempt was made to study the soil water movement under two type of plastic mulch (black and white) with drip irrigated eggplant on a line source dripper. Both spatial and

\section{Keywords}

Water distribution, Wetted width, Wetted radius, Drip irrigation, Surfer

Article Info

Accepted:

15 April 2019

Available Online:

10 May 2019

temporal variation of wetting pattern was determined in sandy loam soil using surfer 15 software. The layout of the experiment was three treatments tested, black mulched drip irrigation $(\mathrm{BM}+\mathrm{DI})$, white mulched drip irrigation $(\mathrm{WM}+\mathrm{DI})$ and drip irrigation without mulching. The results of the study indicated that DI + BM and DI + WM treatments distinctly decreased water applied in the order of DI $+\mathrm{WM}<\mathrm{DI}+\mathrm{BM}<\mathrm{DI}$. Therefore, drip irrigation in combination with plastic mulch especially black mulch to be more effective irrigation method while may help to improve water use efficiency and yield of eggplant. Exponential, Linear, Logarithmic, polynomial and power model were fitted to horizontal and vertical water movement for different time intervals. The result showed that power and polynomial model with $\mathrm{R}^{2}$ value equal to 0.9832 and 0.9804 was the best fitting model in predicting horizontal and vertical water movement. The results from this study will be useful in addressing the most challenging issues like selection of emitter flow rate, dripper spacing based on water requirement of crop and designing the entire drip irrigation system.
\end{abstract}

\section{Introduction}

Water management is a key factor in agricultural production. India shares $17 \%$ of global production with $2.4 \%$ land and $4.0 \%$ of world water resource (Singh et al., 2006).Hence efficient utilization of available water resource is mandatory in India. Around $90 \%$ of water resources are used for agriculture and allied activities in India. Out of these only $50 \%$ of water is used by plants and remaining is wasted either evaporation or deep percolation. This is because of traditional methods are practiced for irrigation. Widely known best water saving irrigation technique is the drip irrigation system. In this method, irrigation water is directly applied to the plant root zone, which minimizes the evaporation, percolation and other water losses (Suryavanshi et al., 2015). 
The velocity of water affects the horizontal and vertical water distribution in soil. In surface drip irrigation, water distribution depends on many factors like soil properties, discharge rate of the dripper, amount of water applied in each irrigation and water uptake by plants (Mallikarjun Reddy et al., 2018). Those parameters are useful for designing and operating drip irrigation system. Among the soil physical properties, the water distribution is significantly affected by soil texture. Several empirical models are available to estimate the wetting front from the surface and subsurface drip irrigation system. Schwartzman and Zur (1986) developed an empirical model to predict the wetted front under different operating time and different discharge rate. Liu and $\mathrm{Xu}$ (2018) estimated wetting pattern under different application time on substrate drip irrigation system. AlOgaidi et al., (2016) conducted laboratory experiment to determine the wetting depth and radius using empirical model. Acar et al., (2009) studied wetting pattern to determine the lateral and emitter spacing under trickle irrigation system. Kandelous and Šimůnek, (2010) compared numerical, analytical, empirical models to estimate wetting patterns for surface and subsurface drip irrigation system. This study attempts to determine the spatial and temporal distribution of water in different depth of soil which will be useful for designing and operating a drip irrigation system (DIS).

\section{Materials and Methods}

The study was conducted at Central Farm of Agricultural Engineering College and Research Institute, Kumulur, Tamil Nadu (Latitude: 10 ${ }^{\circ} 92^{\prime} \mathrm{N}$; Longitude: 78 $82^{\prime} \mathrm{E}$; $62 \mathrm{~m}$ above the Mean Sea Level). The average annual precipitation is about $881.412 \mathrm{~mm}$ (Vaidheki and Arulanandu, 2017). Soil samples were collected from the experimental field at different depths. By using international Robinson pipette method, the soil texture was found to be an average value of $74 \%$ sand, $14 \%$ silt, and $12 \%$ clay, which belongs to sandy loam soil. By using double ring in filtrometer test, the infiltration rate was determined as $1.71 \mathrm{~cm} \mathrm{~h}^{-1}$ (Mashayekhi et al., 2016). The field capacity and wilting point for the soil were estimated by using pressure plate apparatus such as $22.26 \%$ and $9.52 \%$.Bulk density of the soil sample was $1.413 \mathrm{~g} / \mathrm{cc}$ it was determined by core cutter method. Similarly (Zhang et al., 2012 and Laulina et al., 2019) also obtained field capacity of sandy loam soil was in the range of $21-23 \%$.

The Eggplant (Solanum melongena L.) variety Dhruva F1 selected for the experiment. The study was conducted for the season November 2018 to March 2019, on one side of the each furrow by keeping rowto-row and plant-to-plant distance $90 \mathrm{~cm}$ and $45 \mathrm{~cm}$ respectively. The layout of the experiment was three treatments tested, black mulched drip irrigation $(\mathrm{BM}+\mathrm{DI})$, white mulched drip irrigation (WM+DI) and drip irrigation without mulching as shows in (Fig. 1). The irrigation was carried out line source of drip irrigation system with emitters 4lph spaced $45 \mathrm{~cm}$ apart, by each plant, on $16 \mathrm{~mm}$ (ID) laterals, one per row of eggplant. The emitters operate at a pressure of $1 \mathrm{~kg} / \mathrm{cm}^{2}$, which was controlled with bypass arrangement.

The soil water movement was determined using tensiometers for maximum rooting depth of eggplant. Tensoimeter was calibrated in the field by correlating with tension and volumetric water content measured by gravimetric method. Soil water retention curves were given in Figure 2. Moisture reading was taken at horizontal and vertical $10 \mathrm{~cm}$ interval to the plant just after irrigation, 24hafter irrigation and 48h after irrigation for determination of change in soil water storage. 
Contour map was plotted from the data recorded during the experimental field for discharge rate of 4lph using surfer 15 software.

\section{Measurement of Horizontal and vertical water movement}

The DIS with lateral having discharge of 4lph per meter length was installed in the field. The laterals have line source dripper with dripper spacing of $45 \mathrm{~cm}$. A pit was dug across wetted depth and along the length of the drip lateral, this operation was done manually. The horizontal and vertical wetted zone was measured at $10 \mathrm{~min}, 20 \mathrm{~min}, 30 \mathrm{~min}, 50 \mathrm{~min}$, $60 \mathrm{~min}, 70 \mathrm{~min}, 80 \mathrm{~min}, 90 \mathrm{~min}, 100 \mathrm{~min}, 120$ min and $140 \mathrm{~min}$ after operation of DIS. The measurement was done using meter scale as shown in Figure 3.

\section{Description of various models}

\section{Statistical modeling}

The statistical analysis was done to find out the best wetting front model at different operating time in the line source drip irrigation system. The statistical models used were Exponential, Linear, Logarithmic, Polynomial and Power model. The $\mathrm{R}^{2}$ value and regression equation for all models were estimated in MS excel. Using the best fitting model, the horizontal wetting radius and vertical wetting depth was predicted. A comparison was done between the observed and predicted values of horizontal and vertical water movement.

\section{Empirical modeling}

Schwartzman and Zur (1986) developed an empirical model to estimate the soil water movement from a surface line source. The empirical model was developed using experimental results for sandy loam soil for the flow rate of emitter is 4lph.

$$
\begin{aligned}
& \mathrm{W}=3.71(\mathrm{~V})^{0.42}\left(\frac{K_{g}}{Q}\right)^{-0.084} \\
& \mathrm{Z}=1.15(\mathrm{~V})^{0.66}\left(\frac{K_{g}}{Q}\right)^{0.162}
\end{aligned}
$$

Where $\mathrm{W}$ and $\mathrm{Z}$ are horizontal and vertical soil water movement in meters, similarly $\mathrm{V}$ is the total volume of water applied $\left(\mathrm{m}^{3}\right), \mathrm{q}$ is the emitter discharge rate $\left(\mathrm{m}^{3} \mathrm{~s}^{-1}\right)$, and $K_{s}$ is the soil saturated hydraulic conductivity $\left(\mathrm{ms}^{-1}\right)$.

\section{Results and Discussion}

\section{Water movement in the soil}

The field experiments were carried out to measure the soil water movement in sandy loam soil cropped with eggplant. Field data of soil moisture were taken all the three treatment, but best treatment were selected black mulched drip irrigation (DI+BM) having highest soil moisture values compared to white mulched drip irrigation (WM+DI) and drip irrigation without mulching. Calibration of model was done using the values of soil moisture at root zone depth, the data were observed at just after, 24h, and $48 \mathrm{~h}$ after irrigation. Figure 4 shows the soil water movement measured by tensiometer just after, $24 \mathrm{~h}$ and $48 \mathrm{~h}$ after irrigation drawn by surfer 15 software.

The soil water movement result was done at the end of second month after transplanting was taken. These readings indicate that plastic mulching has a distinct effect on drip irrigation effectiveness through the good estimation of wetting bulb's dimensions under the dripper and understanding its moisture changes in place and time, whereas the use of drip irrigation with plastic mulch reduced both of evaporation from soil surface and water distribution area. Which has extreme effect on irrigation water distribution pattern, root distribution, efficiency of the fertilizers, water use and ultimately on the eggplant 
production quantity and quality, these results are also in agreement with Yaghi et al., (2013).

The results showed that the highest soil moisture values were recorded with black plastic mulch and white plastic mulch compared to bare soil. Generally, all mulches holding moisture content at long time because of plastic mulching sheet control the evaporation and deep percolation losses. So, mulches finding favorable soil environmental conditions and had a positive effect on growth of eggplant and contributed to increasing vegetative growth and yield. These results are also in agreement with Yaghi et al., (2013) and Job et al., (2016).

\section{Prediction of water distribution}

The observed horizontal and vertical water movement in sandy loam soil was plotted against operating time and statistical models were fitted to it. The fitted equations for different models and its respective $\mathrm{R}^{2}$ values are listed in Table 1 for horizontal water movement and Table 2 for vertical water movement. The power and polynomial model having with highest regression co-efficient was found to be the best model for predicting horizontal and vertical water movement.

\section{Comparison of observed and predicted water movement}

A comparison was done between observed and predicted values of wetted width and depth under surface drip irrigation with a line source of water application. The observed radius of wetting and predicted radius of wetting from the power model is depicted in Figure 5. Similarly the observed depth of wetting and predicted depth of wetting from polynomial model is shown in Figure 6. The operating time increases, the wetted radius also increases. Compared to vertical depth of wetting, horizontal radius of wetting pattern was high. It was observed that both set of curves matches closely which indicates good accuracy in prediction. The result was similar to that obtained in the study contained by Mallikarjun Reddy (2018) and Kandelous and Šimůnek (2010) in sandy loam soil.

Table.1 Different model for horizontal water movement

\begin{tabular}{|c|l|l|}
\hline Model & \multicolumn{1}{|c|}{ Equation } & \multicolumn{1}{|c|}{$\mathbf{R}^{\mathbf{2}}$} \\
\hline Exponential & $\mathrm{y}=11.899 \mathrm{e}^{0.0073 \mathrm{x}}$ & $\mathrm{R}^{\mathbf{2}}=0.8102$ \\
\hline Linear & $\mathrm{y}=0.1341 \mathrm{x}+11.325$ & $\mathrm{R}^{2}=0.9039$ \\
\hline Logarithmic & $\mathrm{y}=7.2136 \ln (\mathrm{x})-8.3956$ & $\mathrm{R}^{2}=0.9823$ \\
\hline Polynomial & $\mathrm{y}=-0.001 \mathrm{x}^{2}+0.2799 \mathrm{x}+7.5146$ & $\mathrm{R}^{2}=0.9788$ \\
\hline Power & $\mathrm{y}=3.7101 \mathrm{x}^{0.4161}$ & $\mathrm{R}^{2}=0.9832$ \\
\hline
\end{tabular}

Where $\mathrm{Y}=$ Horizontal advance $(\mathrm{cm}), \mathrm{X}=$ Elapsed time $(\mathrm{min}), \mathrm{R}=$ regression co-efficient

Table.2 Different model for vertical water movement

\begin{tabular}{|c|l|l|}
\hline Model & \multicolumn{1}{|c|}{ Equation } & \multicolumn{1}{c|}{$\mathbf{R}^{\mathbf{2}}$} \\
\hline Exponential & $\mathrm{y}=7.4889 \mathrm{e}^{0.0114 \mathrm{x}}$ & $\mathrm{R}^{2}=0.748$ \\
\hline Linear & $\mathrm{y}=0.1632 \mathrm{x}+6.8764$ & $\mathrm{R}^{2}=0.868$ \\
\hline Logarithmic & $\mathrm{y}=8.8733 \ln (\mathrm{x})-17.498$ & $\mathrm{R}^{2}=0.9632$ \\
\hline Polynomial & $\mathrm{y}=-0.0015 \mathrm{x}^{2}+0.385 \mathrm{x}+1.0792$ & $\mathrm{R}^{2}=0.9804$ \\
\hline Power & $\mathrm{y}=1.1521 \mathrm{x}^{0.6615}$ & $\mathrm{R}^{2}=0.9531$ \\
\hline
\end{tabular}

Where $\mathrm{Y}=$ Vertical advance $(\mathrm{cm}), \mathrm{X}=$ Elapsed time $(\mathrm{min}), \mathrm{R}=$ regression co-efficient 
Fig.1 Layout of eggplant experiment and irrigation system at AEC\&RI Kumulur, Trichy, TN

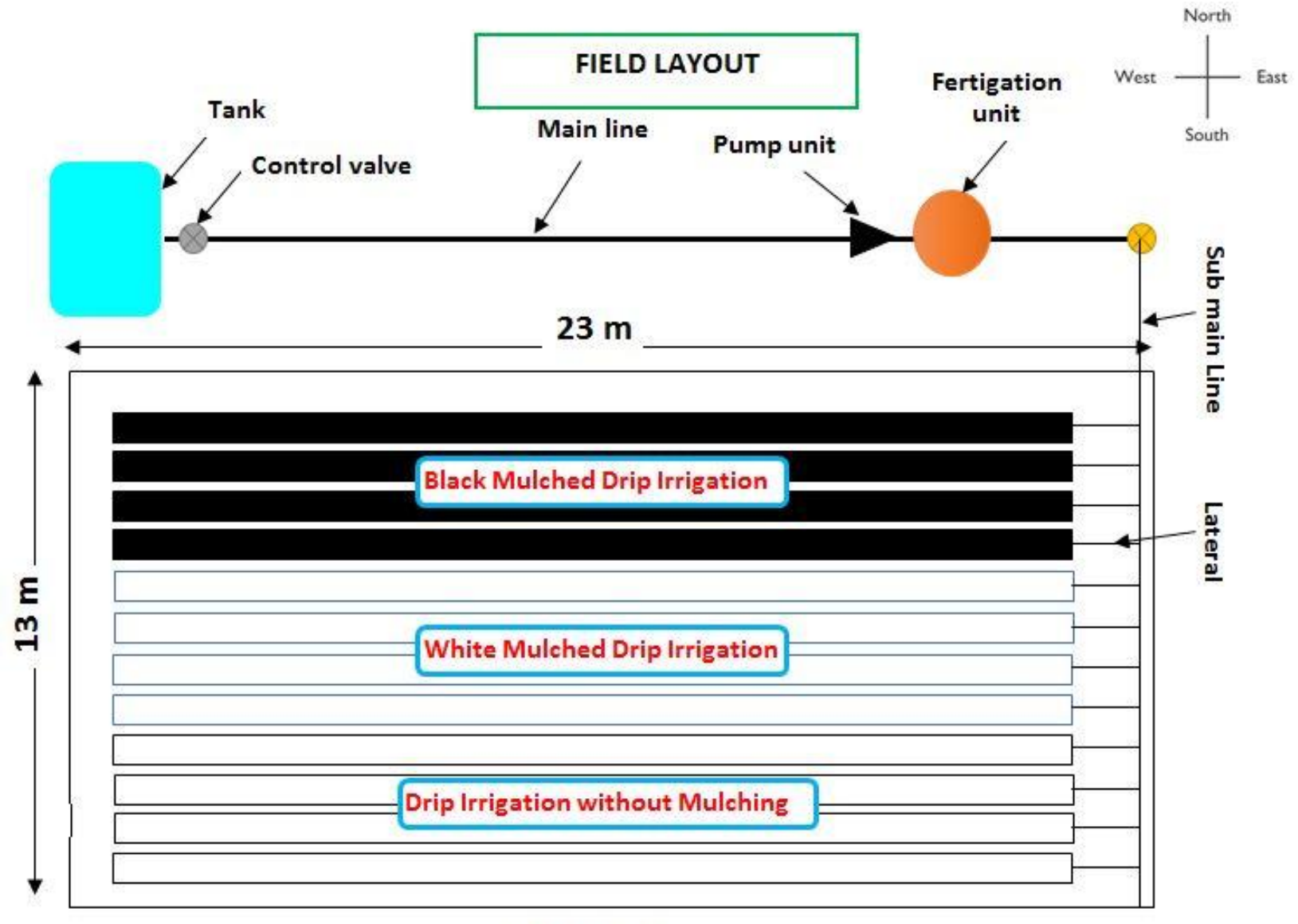

Top view

Fig.2 Soil water retention curve

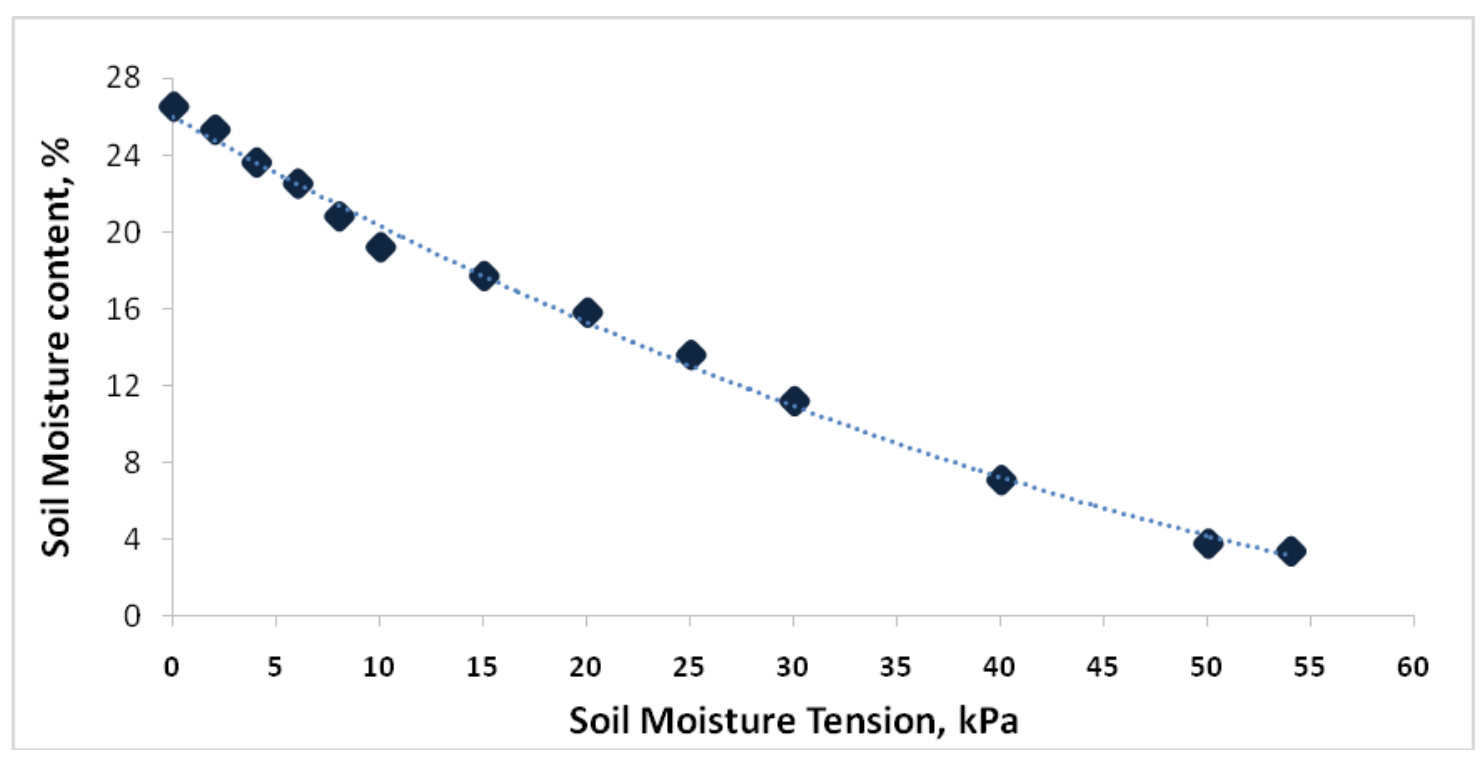


Fig.3 Wetted zone at 60 min after irrigation a) Horizontal wetted zone, b) Vertical wetted zone

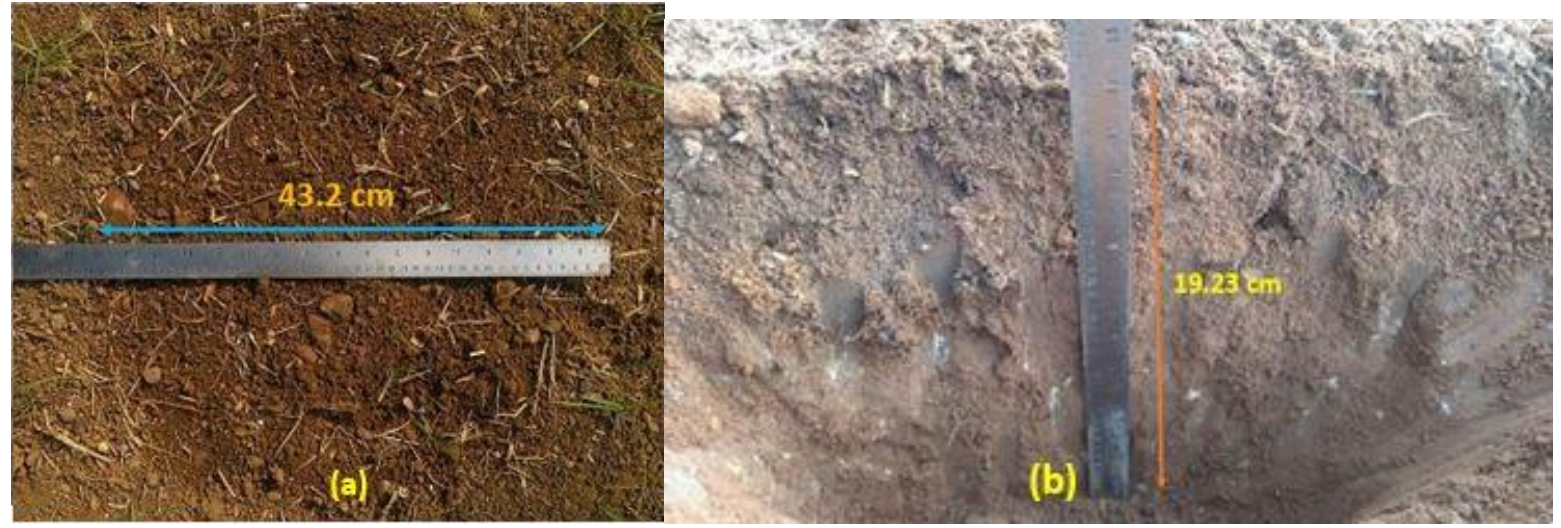

Fig.4 Soil water movement profile for just after, $24 \mathrm{~h}$ and $48 \mathrm{~h}$ after irrigation

\section{Just after irrigation}
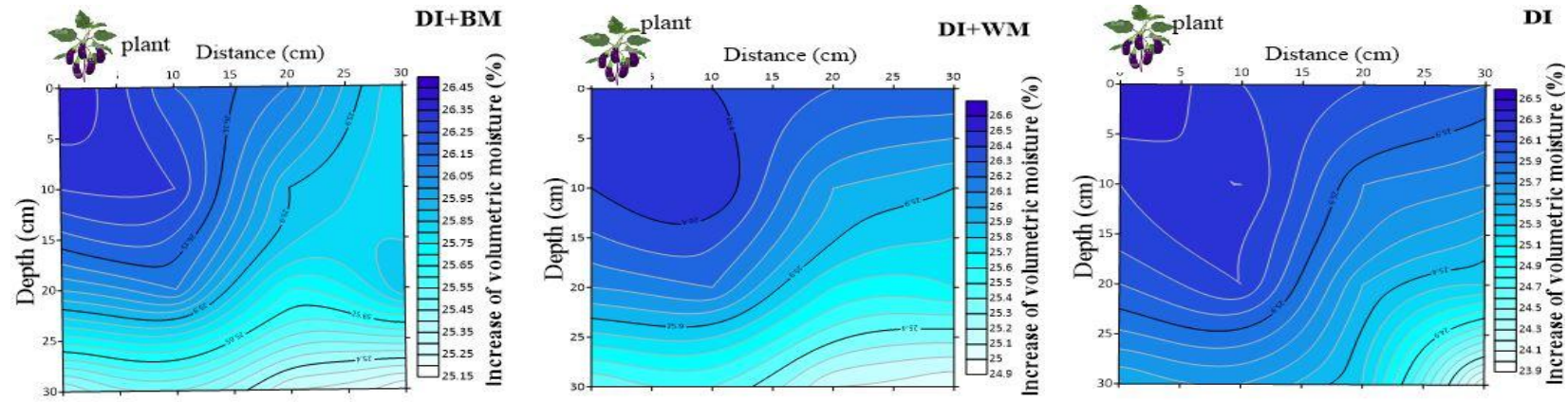

\section{4h after irrigation}
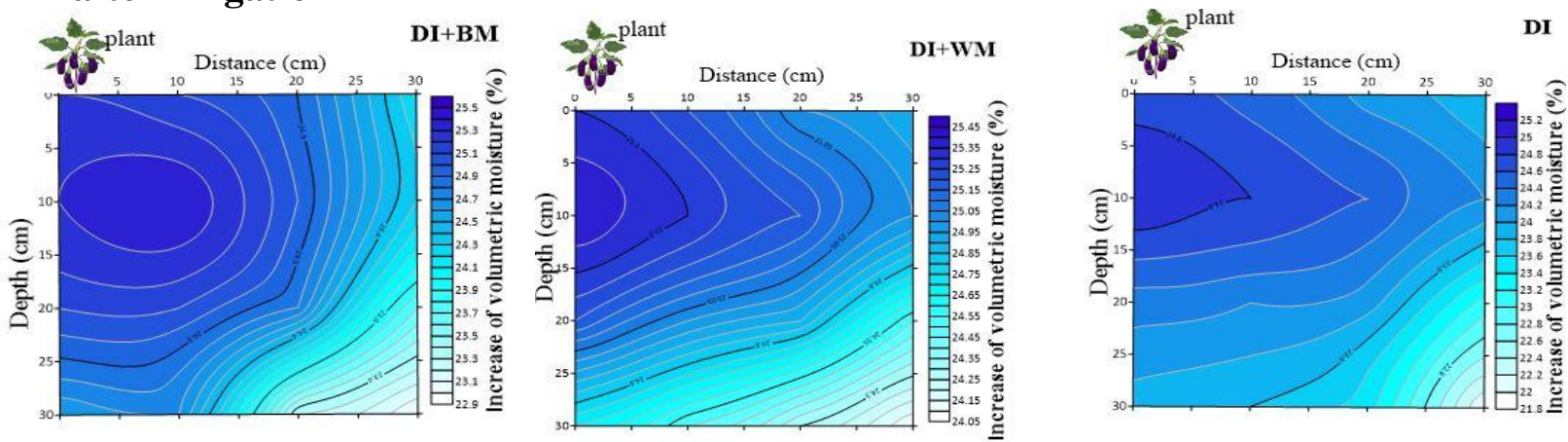

\section{8h after irrigation}
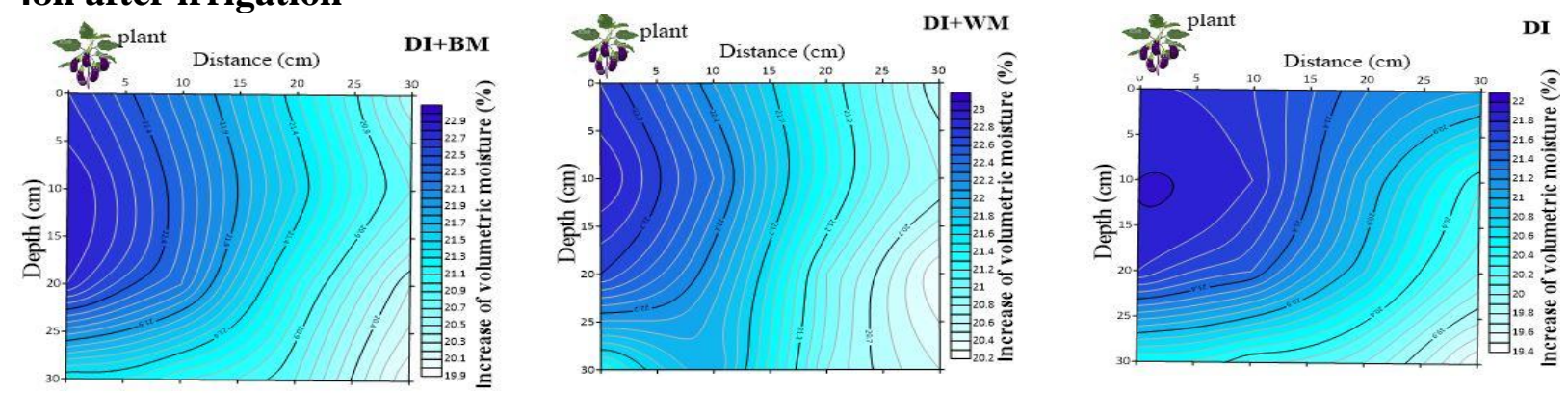
Fig.5 Comparison of radius of wetting

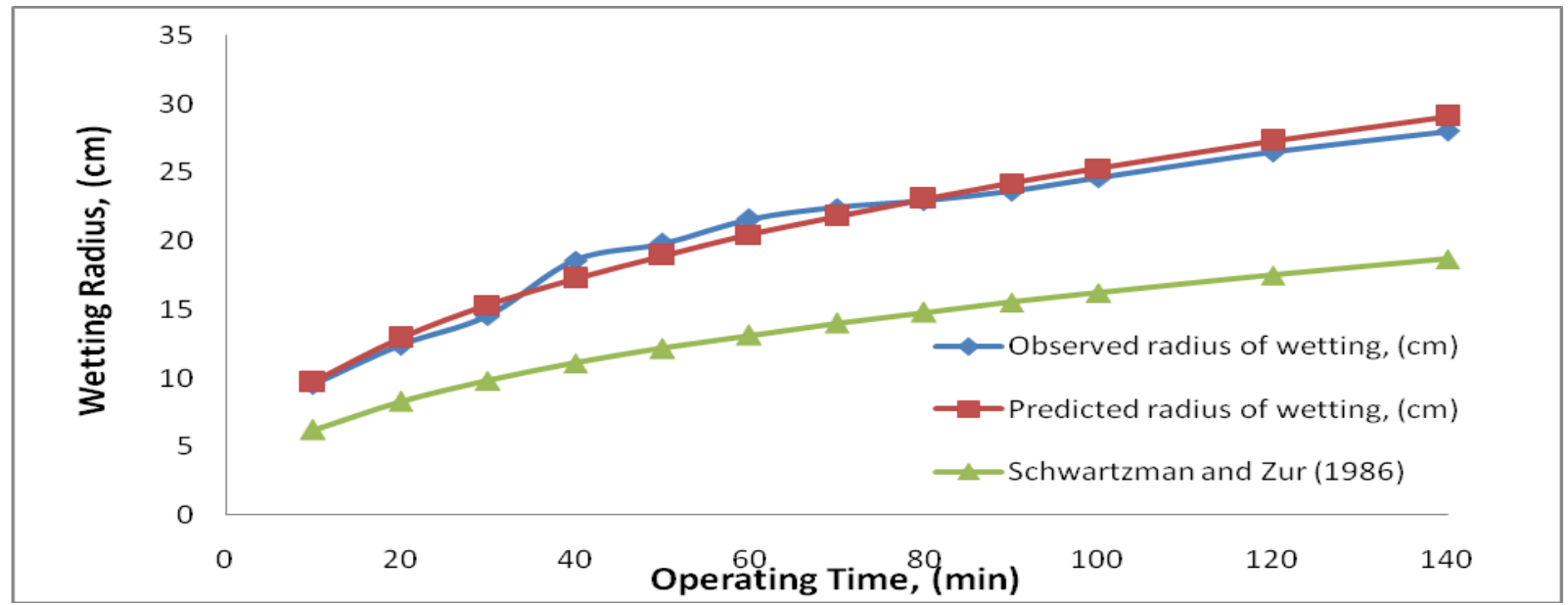

Fig.6 Comparison of depth of wetting

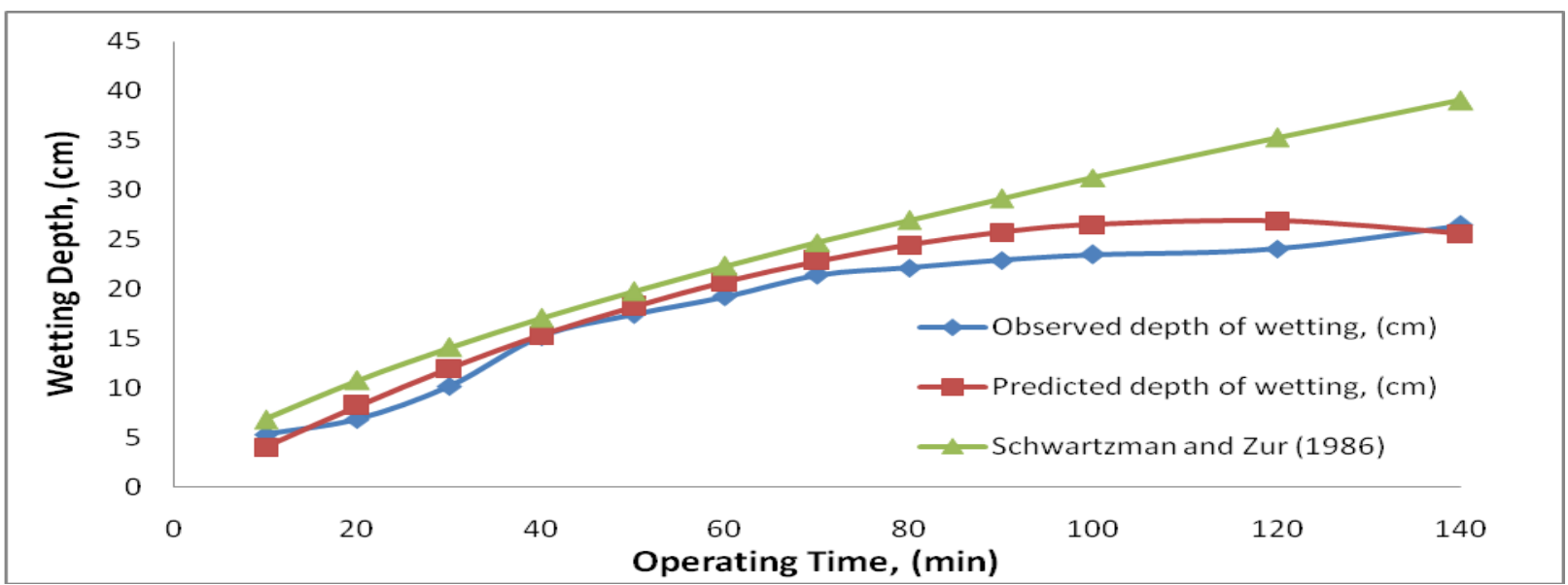

In conclusion, the horizontal and vertical water movement for different time intervals was measured and presented graphically. Soil moisture depletion in mulched field was lesser than non-mulched plots. The results of the study indicated that DI + BM and DI + WM treatments distinctly decreased water applied in the order of DI $+\mathrm{WM}<\mathrm{DI}+\mathrm{BM}$ $<$ DI. However, combined use of drip irrigation and plastic mulch was more appropriate. Therefore, drip irrigation in combination with plastic mulch especially black mulch to be more effective irrigation method while may help to improve water use efficiency and yield of eggplant. The horizontal radius of wetting was found to be higher compared to vertical depth. Power and Polynomial models were fitted to the horizontal and vertical water movement and best fitting model was identified.

\section{References}

Acar, B., Topak, R., and Mikailsoy, F. (2009). Effect of applied water and discharge rate on wetted soil volume in loam or clay-loam soil from an irrigated trickle source. African Journal of Agricultural Research, 4(1), 049-054. 
Al-Ogaidi, A. A., Wayayok, A., Rowshon, M. K., and Abdullah, A. F. (2016). Wetting patterns estimation under drip irrigation systems using an enhanced empirical model. Agricultural Water Management, 176, 203-213.

Job, M., Bhakar, S. R., Singh, P. K., Tiwari, G. S., Sharma, R. K., Lakhawat, S. S., and Sharma, D. (2016). Water Requirement and Soil Moisture Distribution Studies of Drip Irrigated Onion Crop Under Plastic Mulched and Non Mulched Condition. International Journal of Science, Environment and Technology, 5(1), 176-184.

Kandelous, M. M., and Šimůnek, J. (2010). Comparison of numerical, analytical, and empirical models to estimate wetting patterns for surface and subsurface drip irrigation. Irrigation Science, 28(5), 435-444.

Laulina, K., Hasan, M., and Singh, D. K. (2019). Response of different colour plastic mulches on water dynamics under drip fertigated greenhouse capsicum (Capsicum annultin). Indian Journal of Agricultural Sciences, 89(3), 469-474.

Liu, Z., and Xu, Q. (2018). Wetting patterns estimation in cultivation substrates under drip irrigation. Desalination and water treatment, 112, 319-324.

Mallikarjun Reddy, M.S. Ayyanagowdar and Nemichandrappa, M. 2018. Characterize the Moisture Distribution Pattern in Drip Irrigation under Sandy Loam Soil.Int.J.Curr.Microbiol.App.Sci. 7(4): 2915-2923.

Mashayekhi, P., Ghorbani-Dashtaki, S., Mosaddeghi, M. R., Shirani, H., and
Nodoushan, A. R. M. (2016). Different scenarios for inverse estimation of soil hydraulic parameters from double-ring infiltrometer data using HYDRUS2D/3D. International agrophysics, 30(2), 203-210.

Schwartzman, M., and Zur, B. (1986). Emitter spacing and geometry of wetted soil volume. Journal of Irrigation and Drainage Engineering, 112(3), 242253.

Singh, D., Rajput, T., Sikarwar, H., Sahoo, R., and Ahmad, T. (2006). Simulation of soil wetting pattern with subsurface drip irrigation from line source. Agricultural water management, 83(1-2), 130-134.

Suryavanshi, P., Buttar, G., and Brar, A. (2015). Micro irrigation for sustainable agriculture: a brief review. Indian Journal of Economics and Development, 11(1), 147-155.

Vaidheki, M. and Arulanandu, U. 2017. Estimating Extreme Temperature at Agricultural Engineering College and Research Institute, Kumulur Station by Using Generalized Extreme Value Distribution.Int.J.Curr.Microbiol.App.S ci. 6(11): 3874-3886.

Yaghi, T., Arslan, A., and Naoum, F. (2013). Cucumber (Cucumis sativus, L.) water use efficiency (WUE) under plastic mulch and drip irrigation. Agricultural water management, 128, 149-157.

Zhang, R., Cheng, Z., Zhang, J., and Ji, X. (2012). Sandy loam soil wetting patterns of drip irrigation: a comparison of point and line sources. Procedia Engineering, 28, 506-511.

\section{How to cite this article:}

Rahul, R. and Manikandan, M. 2019. Spatial and Temporal Variation of Soil Water Movement Modeling under Line Source Dripper. Int.J.Curr.Microbiol.App.Sci. 8(05): 1926-1933. doi: https://doi.org/10.20546/ijcmas.2019.805.223 